\title{
Postintubation airway obstruction caused by a retrotracheal haematoma
}

\author{
Yasuyuki Chida, ${ }^{1}$ Ryota Inokuchi, ${ }^{2}$ Tetsu Sasaki, ${ }^{1}$ Kazuaki Shinohara ${ }^{1}$
}

${ }^{1}$ Emergency and Critical Care Medicine, Ohta Nishinouchi Hospital, Koriyama, Fukushima, Japan

${ }^{2}$ Emergency and Critical Care Medicine, The University of Tokyo Hospital, BunkyoKu, Japan

\section{Correspondence to} Dr Ryota Inokuchi, inokuchir-icu@h.u-tokyo.ac.jp

Accepted 7 May 2016

\section{DESCRIPTION}

A 70-year-old man was admitted for traffic accident-related blunt chest trauma. He was taking aspirin and clopidogrel for a previous myocardial infarction. On admission, his initial vital signs were stable, but he had stridor and paradoxical respirations during examination. Contrast-enhanced CT (CECT) showed a retrotracheal haematoma without extravasation (figure 1). Postintubation bronchial fibrescope, oesophageal fibrescope and oesophagography showed neither tracheal nor oesophageal injuries. On day 4, after the patient moved while being intubated, the paradoxical respirations suddenly recurred. CECT revealed stenosis in the main bronchi below the site of intubation tube placement, likely due to an enlarged retrotracheal haematoma without extravasation (figure 2). Deeper reintubation improved the respiration. However, negative pressure pulmonary oedema occurred. After the haematoma and oedema resolved (day 10), the patient was extubated. Antiplatelet therapy was restarted, and he was discharged without complications.

Retrotracheal haematoma is caused by aortic injuries, bleeding of the mediastinal vein, ruptured aneurysm of the inferior thyroid artery or vertebral fractures. ${ }^{1}$ It is identified through extravasation on CECT. $^{2}$ Most retrotracheal haematomas without extravasation resolve with only airway intubation. ${ }^{3}$ However, retrotracheal haematomas can cause airway obstruction, especially in patients receiving antiplatelet and anticoagulation therapy. Such

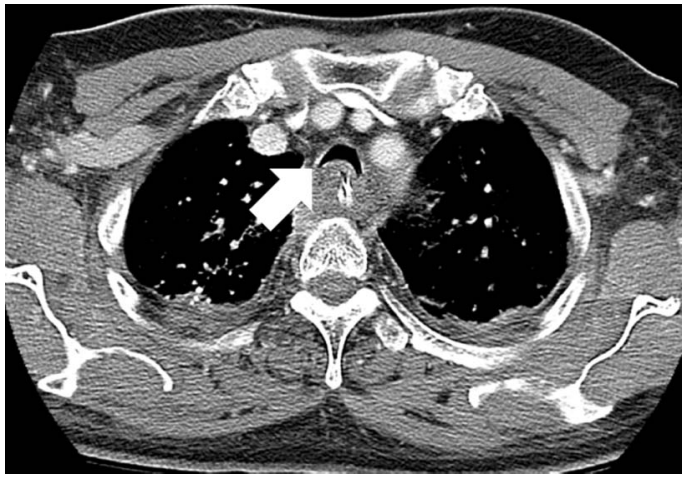

Figure 1 Stenosis in the main bronchi due to a retrotracheal haematoma (arrow).

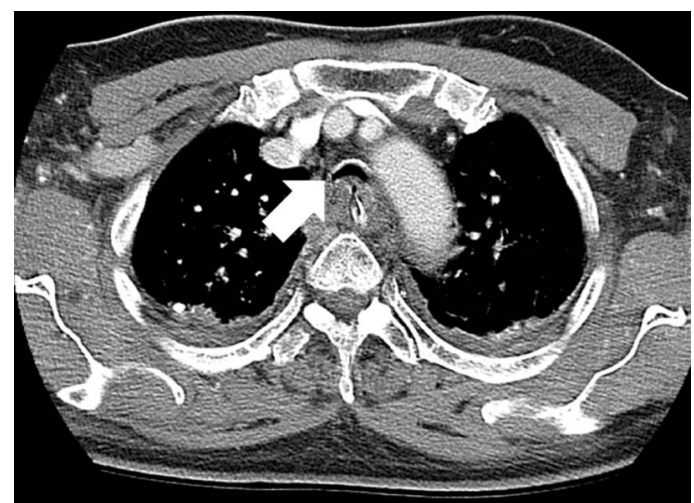

Figure 2 On day 4, stenosis in the main bronchi, below the intubation tube, due to a retrotracheal haematoma (arrow).

patients should therefore be closely monitored, even when they are intubated.

\section{Learning points}

- Retrotracheal haematoma should be considered after blunt chest trauma.

- Retrotracheal haematomas can cause airway obstruction, even with intubation.

Contributors YT, TS and KS contributed to patient management. YT and RI drafted the initial manuscript. All the authors contributed to writing the manuscript. All the authors have provided written consent for publication.

Competing interests None declared.

Patient consent Not obtained.

Provenance and peer review Not commissioned; externally peer reviewed.

\section{REFERENCES}

1 Kubota $\mathrm{H}$, Endo $\mathrm{H}$, Noma $\mathrm{M}$, et al. Airway obstruction by a retropharyngeal hematoma secondary to thoracic aortic aneurysm rupture. J Cardiothorac Surg 2013;8:232.

2 Birkholz T, Kröber S, Knorr C, et al. A retropharyngeal-mediastinal hematoma with supraglottic and tracheal obstruction: the role of multidisciplinary airway management. J Emerg Trauma Shock 2010;3:409-11.

3 Pasumarthy L. Posterior mediastinal hematoma - a rare case following a fall from standing height: a case report. J Med Case Rep 2007;1:185. 


\section{Images in...}

Copyright 2016 BMJ Publishing Group. All rights reserved. For permission to reuse any of this content visit http://group.bmj.com/group/rights-licensing/permissions.

BMJ Case Report Fellows may re-use this article for personal use and teaching without any further permission.

Become a Fellow of BMJ Case Reports today and you can:

- Submit as many cases as you like

- Enjoy fast sympathetic peer review and rapid publication of accepted articles

- Access all the published articles

- Re-use any of the published material for personal use and teaching without further permission

For information on Institutional Fellowships contact consortiasales@bmjgroup.com

Visit casereports.bmj.com for more articles like this and to become a Fellow 